\title{
Research to Improve ShakeAlert Earthquake Early Warning Products and Utility
}
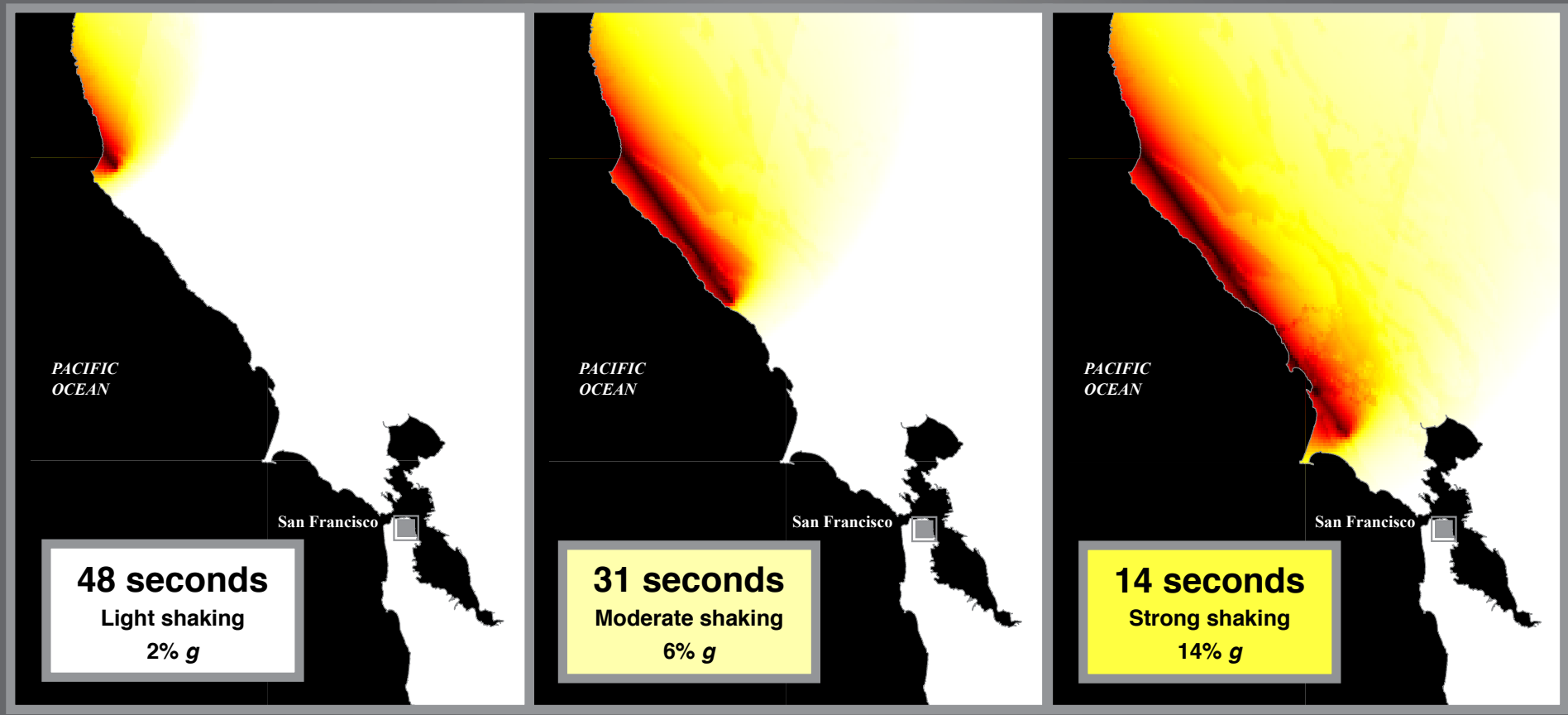

Open-File Report 2018-1131

U.S. Department of the Interior

U.S. Geological Survey 
Cover. Maps of potential warning times for different levels of expected ground motion in the city of San Francisco, California, from an evolving rupture on the northern San Andreas Fault. Background color is the peak ground acceleration with red indicating severe or higher ground motions. Panels from left to right show the progression of the earthquake as it grows in size and ruptures closer to the city. The expected ground motions in San Francisco become large only when the rupture approaches the city. The final size and rupture extent of an earthquake cannot be predicted in advance, so warning times for strong ground motion will be short. Longer warning times are possible if a lower threshold is used to issue an alert. Based on results from Minson and others (2018). \%, percent; $g$, gravitational acceleration. 


\section{Research to Improve ShakeAlert Earthquake Early Warning Products and Utility}

By Elizabeth S. Cochran, Brad T. Aagaard, Richard M. Allen, Jennifer Andrews, Annemarie S. Baltay, Andrew J. Barbour, Paul Bodin, Benjamin A. Brooks, Angela Chung, Brendan W. Crowell, Douglas D. Given, Thomas C. Hanks, J.

Renate Hartog, Egill Hauksson, Thomas H. Heaton, Sara McBride, Men-Andrin

Meier, Diego Melgar, Sarah E. Minson, Jessica R. Murray, Jennifer A. Strauss, and Douglas Toomey

Open-File Report 2018-1131 


\section{U.S. Department of the Interior \\ RYAN K. ZINKE, Secretary}

\section{U.S. Geological Survey \\ James F. Reilly II, Director}

U.S. Geological Survey, Reston, Virginia: 2018

For more information on the USGS - the Federal source for science about the Earth,

its natural and living resources, natural hazards, and the environment-visit

https://www.usgs.gov/ or call 1-888-ASK-USGS (1-888-275-8747).

For an overview of USGS information products, including maps, imagery, and publications, visit https://store.usgs.gov/.

Any use of trade, firm, or product names is for descriptive purposes only and does not imply endorsement by the U.S. Government.

Although this information product, for the most part, is in the public domain, it also may contain copyrighted materials as noted in the text. Permission to reproduce copyrighted items must be secured from the copyright owner.

Suggested citation:

Cochran, E.S., Aagaard, B.T., Allen, R.M., Andrews, J., Baltay, A.S., Barbour, A.J., Bodin, P., Brooks, B.A., Chung, A., Crowell, B.W., Given, D.D., Hanks, T.C., Hartog, J.R., Hauksson, E., Heaton, T.H., McBride, S., Meier, M-A., Melgar, D., Minson, S.E., Murray, J.R., Strauss, J.A., and Toomey, D., 2018, Research to improve ShakeAlert earthquake early warning products and their utility: U.S. Geological Survey Open-File Report 2018-1131, 17 p., https://doi.org/10.3133/ ofr20181131.

ISSN 2331-1258 (online) 


\section{Acknowledgments}

The authors thank those who provided input during the development and revision of this document, including Ruth Harris, Stephen Hickman, Keith Knudsen, William Leith, and Andrew Michael.

\section{Contents}

Executive Summary

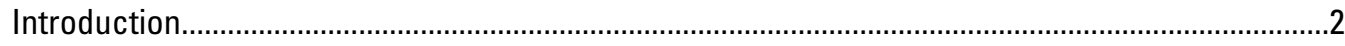

Design of the ShakeAlert Operational System ……….........................................................

Current System Performance and Identified Needs ................................................................

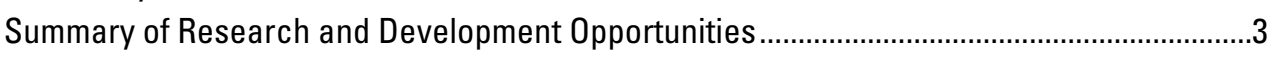

Challenge 1-Understand EEW Capabilities and User Needs .....................................................

Theoretical Capabilities of EEW Systems...........................................................................

System Performance Metrics and Uncertainty Measures.....................................................

Public Alert Messaging..............................................................................................................

Technical User Needs and Development of a Cost-Benefit Framework..................................

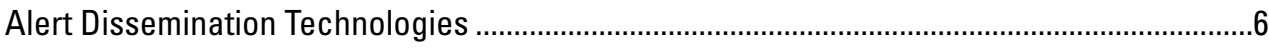

Evolution of Alert Information and Messaging ……..........................................................

Integrating ShakeAlert and Real-Time Earthquake Information Products ................................

Challenge 2-Make Alerts as Fast and Accurate as Possible .......................................................7

Improved Ground-Motion Predictions ................................................................................

Improved Identification of Seismic Phases in Seismograms .................................................

Development of Ground-Motion-Based Alert Methods ..........................................................

Increased Quality of Point-Source Algorithm Ground-Shaking Predictions ............................9

Increased Quality of Finite-Fault Algorithm Predictions .........................................................

Propagation of Uncertainties and Development of a Bayesian Framework ...........................9

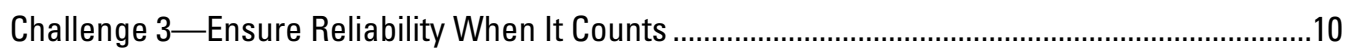

Appropriate Historical Datasets for System Performance Testing .......................................10

Synthetic Waveforms for Performance Testing and Evaluation..............................................10

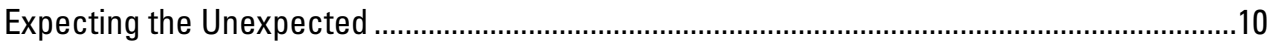

Challenge 4-Explore the Use of New Instrumentation ..............................................................11

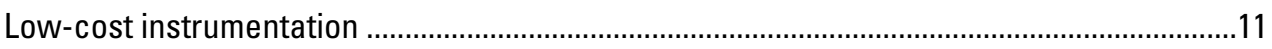

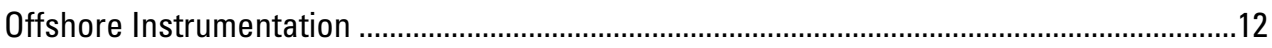

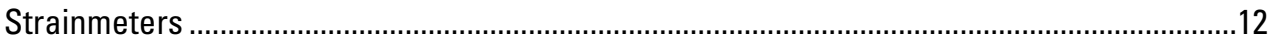

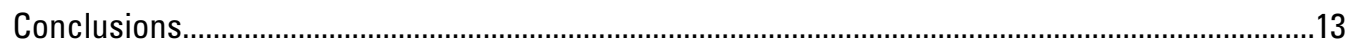

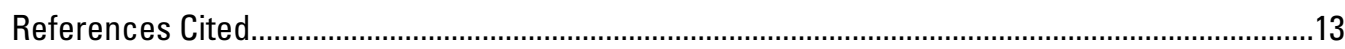




\title{
Abbreviations
}

\author{
ANSS Advanced National Seismic System \\ BART Bay Area Rapid Transit \\ BSM borehole strainmeter \\ EEW earthquake early warning \\ GMPE ground-motion prediction equation \\ GMICE ground-motion-to-intensity conversion equation \\ GNSS global navigation satellite system \\ GPS global positioning system \\ IPE intensity prediction equation \\ JCCEO Joint Committee on Communication, Education, and Outreach \\ MEMS microelectromechanical system \\ MMI Modified Mercalli Intensity \\ OBS ocean-bottom seismometers \\ PBO Plate Boundary Observatory \\ PDS peak dynamic strain \\ PGA peak ground acceleration \\ PGV peak ground velocity \\ PGD peak ground displacement \\ UC University of California \\ USGS U.S. Geological Survey \\ XML extensible markup language
}




\title{
Research to Improve ShakeAlert Earthquake Early Warning Products and Utility
}

\author{
By Elizabeth S. Cochran, Brad T. Aagaard, Richard M. Allen, Jennifer Andrews, Annemarie S. Baltay, Andrew \\ J. Barbour, Paul Bodin, Benjamin A. Brooks, Angela Chung, Brendan W. Crowell, Douglas D. Given, Thomas \\ C. Hanks, J. Renate Hartog, Egill Hauksson, Thomas H. Heaton, Sara McBride, Men-Andrin Meier, Diego \\ Melgar, Sarah E. Minson, Jessica R. Murray, Jennifer A. Strauss, and Douglas Toomey
}

\section{Executive Summary}

Earthquake early warning (EEW) is the rapid detection of an earthquake and issuance of an alert or notification to people and vulnerable systems likely to experience potentially damaging ground shaking. The level of ground shaking that is considered damaging is defined by the specific application; for example, manufacturing equipment may experience damage at a lower intensity ground shaking than would cause damage to a building. Along the West Coast of the United States, the warning times for ground shaking could range as high as tens of seconds for moderate levels of ground shaking, or potentially longer, if a lower ground-shaking threshold is used to issue alerts. However, it is not always possible to provide advance warning of ground shaking, particularly for locations close to an earthquake that are most likely to experience very strong ground shaking. EEW alerts may be useful to individuals who can use a few seconds to move to a safe zone and to electromechanical systems that can take automatic actions to reduce damage and injuries. An EEW system, ShakeAlert, has been under development in the United States since 2006. Federal and State governments, as well as the private sector, are now investing in the ShakeAlert prototype system that will, when completed, become an operational public system for the West Coast of the United States.

While the current prototype is delivering alerts to test users, improvements to the accuracy, timeliness, and utility of the alerts are needed. For this reason, it is essential that the ShakeAlert system be continuously improved through targeted research, involving not only the current ShakeAlert partner organizations, but also the broader scientific, engineering, and emergencyresponse communities. To this end, this report describes the opportunities for improvement that can be addressed through research and development over the next 5 years.

Our recommendations are organized into four areas: (1) understand EEW capabilities and user needs, (2) make alerts as fast and accurate as possible, (3) ensure reliability when it counts, and (4) explore the use of new instrumentation.

The first challenge is to understand EEW capabilities and user needs. EEW must deliver actionable information to people and to automated systems to mitigate short- and longterm impacts of damaging ground shaking, so development of EEW must be motivated by the needs of users. Within this challenge, we must study the technical capabilities and limitations of EEW in general, and the ShakeAlert system specifically. This includes development of performance metrics that assess the timeliness and accuracy of alerts to understand the value and utility of the ShakeAlert EEW product(s) for various user groups, including different industry sectors, emergency-management agencies, and the public. Research is needed to define the alerting choices that maximize the utility of the system for users and to determine what the available communication pathways are for providing timely alert information. Additionally, we engage users to assess how alerts will be used by different sectors to mitigate losses and to inform EEW product design. Further, social-science research is needed to develop alert messaging, including what relevant prior and follow-up information are required, to ensure effective use of alerts.

The second challenge is to make alerts as fast and as accurate as possible. The timeliness and accuracy of an EEW alert is important because it will set in motion a series of actions and downstream products. An EEW alert will trigger notification across emergency-alert systems and across multiple communication channels to populations in impacted regions. The EEW alert region may grow as the earthquake fault-rupture length increases, and the EEW system's characterization of it, evolves. We must continue research into new or improved seismic and geodetic waveform-processing methods necessary to rapidly characterize the expected ground shaking and associated uncertainties. It is important to thoroughly evaluate whether new methods improve alerts through more accurate ground-motion estimates and (or) reduced latencies (that is, longer warning times). New methods could include tracking the extent of a large rupture in real time (known as finite-fault algorithms) and ground-motionbased EEW algorithms. Additionally, ground motion predictions could be optimized for each earthquake as the earthquake fault rupture progresses by using, for example, event terms to shift ground-motion curves for more (or less) energetic ruptures. 
The third challenge is to ensure reliability when it counts. This challenge requires us to explore approaches that assess the expected performance of ShakeAlert across the range of earthquake magnitudes, locations, and depths that may occur within the alerting region. Large, damaging earthquakes and their associated aftershock sequences matter most for hazard and for EEW, but these large-earthquake sequences occur infrequently. We expect ShakeAlert to respond robustly to these large-earthquake sequences despite potentially long periods of relative seismic quiescence in the intervening years, and in spite of inevitable communication challenges that arise during and after a large earthquake. We must develop methods to utilize the broadest available datasets to test EEW performance, including ground-motion data recorded in other parts of the world. The observational period for large, damaging earthquakes in any particular region has been short in comparison to estimated large-earthquake recurrence times. Ground-motion records for very large, damaging western United States events and major aftershock sequences do not yet exist, nor do data exist for all potential sources of noise and spurious signals that ShakeAlert must be "tuned" to reject. In addition, robust synthetic data could provide the flexibility to test a wider range of earthquake magnitude, tectonic-setting, and noise scenarios than are covered by existing observational data. Synthetic ground-motion data must be thoroughly vetted against records of smaller magnitude earthquakes to ensure that they accurately capture both the onset and the amplitude of the ground shaking.

The final challenge is to explore the use of new instrumentation. The development of EEW around the world to date has focused on the use of high-quality, scientific-grade seismic and geodetic instrumentation. The use of additional types of instrumentation or information may also improve EEW products by filling gaps in sensor coverage in countries that already have dense seismic networks or enable EEW in countries without such networks. We must keep up with these developments and continuously assess their value in supplementing existing EEW systems, such as ShakeAlert, or enabling EEW where such systems do not exist. Such developments include low-cost instrumentation with microelectromechanical system (MEMS) sensors and global positioning system (GPS)/global navigation satellite system (GNSS) antennas embedded in low-cost consumer electronics, sea-floor seismometers, geodetic instrumentation deployed along the Cascadia and Alaska megathrust margins of western North America, and borehole strainmeters that are already deployed across the region.

\section{Introduction}

Earthquake early warning (EEW) systems propose to trigger actions that may mitigate losses and reduce injuries from earthquakes (for example, Nakamura, 1988; Wu and others, 1998; Kanamori, 2005; Strauss and Allen, 2016).
EEW can provide up to tens of seconds of warning for moderate ground shaking (Modified Mercalli Intensity [MMI] IV-VI) (Meier and others, 2017; Minson and others, 2018); however, it is not always possible to provide advance warning particularly for locations close to an earthquake that may experience very strong ground shaking. EEW systems are operational in several countries around the world, including Mexico, Japan, Turkey, China, Taiwan, Italy, and Romania (Espinosa-Aranda and others, 1995; Hoshiba and others, 2008; Allen and others, 2009). ShakeAlert is an EEW system being developed for high-seismic-risk areas in the United States (Given and others, 2014). ShakeAlert development began in 2006 and is currently operating as a prototype system in California, Washington, and Oregon (Kohler and others, 2018). In 2018, ShakeAlert will begin a gradual public rollout, and expansion of public alerting will occur after the system attains the necessary sensor coverage, system alert performance metrics are achieved, and training and education of users is completed.

\section{Design of the ShakeAlert Operational System}

The ShakeAlert system uses the earthquake-monitoring infrastructure of the Advanced National Seismic System (ANSS), a nationwide group of cooperating seismic networks coordinated by the U.S. Geological Survey (USGS) (Given and others, 2014). Additional investment and development are being undertaken to bolster the ability of the seismic networks on the West Coast of the United States to provide the rapid and dense ground-motion observations necessary for issuing earthquake alerts. Sufficient density (seismic-station spacing of $\sim 20$ kilometers [km] or less) of recording sensors is needed near earthquake-generating faults that can generate strong ground shaking (Kuyuk and Allen, 2013). Communication of ground-motion data from field stations to central processing sites, with minimal latencies, has become possible through upgrades to data handling (for example, sending seismograms in second or sub-second data packets) and improved telemetry (that is, conversion of dial-up modems to radio and [or] cellular modems). The seismic stations that contribute to ShakeAlert send continuous real-time data back to processing centers by some combination of radio, government-owned microwave, commercial cellular, commercial Internet, commercial frame-relay, satellite, and partner-owned telemetry systems. Further improvements are planned to ensure that seismic-network design and telemetry is optimized for speed, reliability, and redundancy.

EEW seismic-data processing and the generation of alerts takes place at ANSS regional network centers. Groundmotion data are transmitted to the nearest regional ANSS center where EEW-relevant parameters are computed. These EEW parameters are then shared between regional network centers for redundant EEW alert generation. The ShakeAlert operational system for the 2018 gradual public rollout includes an earthquake "point-source" algorithm that 
provides an estimate of the location, magnitude, and origin time of detected earthquakes and a "finite-fault" algorithm that estimates the rupture extent and magnitude of larger earthquakes. These algorithms characterize an evolving earthquake fault rupture by processing seismic-waveform data to detect significant ground shaking and then measure EEW-relevant parameters such as peak ground shaking and the frequency content of the ground shaking. Alert messages are formatted with extensible markup language (XML) and distributed via the Internet to ShakeAlert users.

\section{Current System Performance and Identified Needs}

The Testing and Certification Platform evaluates the performance of the ShakeAlert system using analysis of alerts generated by real-time data and by replay of a test suite of waveforms from historical earthquakes and problematic events (noise spikes, teleseisms, and so forth) (see Cochran and others, 2018, for more information). The ShakeAlert real-time prototype system achieved several milestones over the past few years. The ShakeAlert system detected the 2014 magnitude $(M) 6.0$ South Napa, California, earthquake, and provided an alert 5 seconds before the S-wave arrival to the University of California police on the UC Berkeley campus, which experienced MMI IV at a distance of $38 \mathrm{~km}$ from the epicenter of the South Napa earthquake. An alert was also issued 8 seconds before the S-wave arrival to the emergency operations center in San Francisco, which experienced MMI IV at a distance of $50 \mathrm{~km}$ from the epicenter. In response to the shaking alert, Bay Area Rapid Transit (BART) activated their automated train-slowing system; however, no trains were in operation at the time of the earthquake alert (at 3:24 a.m.) because the earthquake occurred in the early morning.

In southern California, the ShakeAlert system detected the 2015 M3.8 earthquake in View Park (Los Angeles) that occurred at a depth of $11.1 \mathrm{~km}$, resulting in an alert issued 3.4 seconds after the origin time, shortly before the S-wave reached the Earth's surface. Other successful examples include the 2018 M4.4 Hayward Fault earthquake for which the prototype ShakeAlert system issued alerts up to 12 seconds prior to human-felt ground motion (MMI II), and the 2018 M5.3 Santa Cruz Island, California, earthquake for which the system provided as long as 29 seconds advance notification for human-felt ground motion (MMI II).

Evaluations have also identified deficiencies in the ShakeAlert system. The system has issued false alerts caused by misinterpreting ground motion from one earthquake as several simultaneous earthquakes ("split events") and incorrect triggering on noise, timing pulses, or teleseismic arrivals (Cochran and others, 2018). Some alerts are also of lower quality owing to large errors in estimated earthquakesource parameters (magnitude or location), typically in regions of sparse seismic-station coverage or near the edges of the seismic network. Alerts are occasionally not issued for $M 4.5+$ earthquakes, referred to as missed events, though these usually occur in areas where the seismic-station density is low. Since the system went online in February 2016, there have been no missed events with magnitude $M 4.5$ or greater near any major city on the West Coast. The six M4.5+ events that ShakeAlert failed to alert on between February 2016 and May 2018 occurred in remote and (or) offshore regions where there were too few nearby seismic stations to identify the event. Additionally, some alerts have provided correct information, but were issued too late for users to benefit. ShakeAlert must not only accurately detect whether an earthquake is happening, but it must also accurately calculate the expected ground shaking in order to identify which regions or users to alert. Work is currently underway to assess the timeliness and accuracy of ShakeAlert ground-motion estimates.

\section{Summary of Research and Development Opportunities}

A number of research and development opportunities exist that will advance our understanding of EEW and improve the performance of the ShakeAlert system. We detail some of these opportunities here, formulating a set of challenges for the ShakeAlert system. These challenges are to (1) understand EEW capabilities and user needs, (2) make alerts as fast and accurate as possible, (3) ensure reliability when it counts, and (4) explore the use of new instrumentation. We believe these challenges can be met over the next 5 years.

\section{Challenge 1-Understand EEW Capabilities and User Needs}

The goal of the ShakeAlert system is to provide users with advance warning of potentially damaging ground motions so that the users, in turn, can take protective action. The level of ground shaking that is considered as damaging is defined by the specific application; for example, manufacturing equipment may experience damage at a much lower intensity (perhaps MMI IV) than would cause damage to a building (typically MMI VII+). As such, conducting research on the expected capabilities of EEW systems as well as the needs of a diverse user community are central to the design and distribution of alerts.

During an earthquake, EEW algorithms generate a stream of information from the first detection of an earthquake to an expanding characterization of the seismic source that might include information about the extent of the fault rupture and the distribution of slip on the fault. This information is then converted into products (alerts) that are issued to users within geographic regions expected to experience ground shaking exceeding some threshold. The first challenges for EEW are identifying the scientific and technical capabilities of current EEW systems, the types of information most critical for users, how alerts can most efficiently be distributed, and 
how to integrate these alerts with other real-time earthquake information products. These challenges will require a broad collaboration among not only geoscientists, but also researchers in the fields of technology and social sciences.

Continued and expanded engagement between ShakeAlert project members and users is essential. Research and development are needed in the following broad areas:

- Theoretical capabilities of EEW systems;

- System performance metrics and uncertainty measures;

- Public alert messaging, including post-alert information;

- Technical user needs and development of a cost-benefit framework;

- Alert dissemination technologies;

- Evolution of alert information and messaging; and

- Integrating ShakeAlert and other real-time earthquake information products.

\section{Theoretical Capabilities of EEW Systems}

Current work on theoretical capabilities of earthquakesource-based EEW methods indicates that theory-based limitations should be considered when designing an effective system, including considerations of the timeliness of alerts for a physically realistic evolution of earthquake fault rupture (Meier, 2017; Minson and others, 2018) and the accuracy of groundmotion predictions. Additional work is required to assess the expected performance for various measures of ground motion, including peak ground acceleration (PGA), velocity (PGV), and displacement (PGD), and for different earthquake frequency/ magnitude distributions, regional attenuation, rupture behavior, site/basin characteristics, rupture directivity, and so forth. These predictions should be tested against observations, where available. Additionally, we must understand the advantages and disadvantages of algorithms that describe earthquakes using point-source parameters (for example, Allen and Kanamori, 2003; Allen, 2007; Wu and others, 2007; Allen and others, 2009; Böse and others, 2009; Kuyuk and Allen, 2013), algorithms that describe earthquakes using finite-fault parameters (Böse and others, 2012; Allen and Ziv, 2011; Grapenthin and others, 2014; Minson and others, 2014; Crowell and others, 2016), and algorithms that predict expected ground motions from observed ground motions without determining earthquake magnitude, location, or rupture extent (for example, Hoshiba, 2013; Hoshiba and Aoki, 2015; Kodera and others, 2016; Kodera and others, 2018; Yang and others, 2018). The results will allow for a greater understanding of the expected performance of EEW systems that predict ground shaking from source magnitude and location information as well as systems that directly predict expected ground-shaking intensities from the earliest shaking observations.

\section{System Performance Metrics and Uncertainty Measures}

An ideal EEW performance metric would be applicable to any kind of EEW algorithm and any type of earthquake scenario; it would also consider the evolving ground-motionprediction accuracies during an earthquake, from the first alert through to the final alert issued by the EEW system. Such a metric may be the basis for evaluating performance of algorithms in absolute terms (how good are the warnings that EEW systems can provide?) as well as relative to other algorithms or algorithm versions. This approach would enable the community to methodically evaluate the benefit of EEW system modifications on all scales (for example, new algorithms, new features of existing algorithms, and so forth), and to determine which alerting strategies lead to optimal outcomes. Furthermore, it may provide guidance on how ground-motion predictions from multiple algorithms should be combined to produce a more accurate ensemble groundshaking prediction. The metrics should also allow evaluation of the tradeoffs between gain and complexity when different variants of EEW algorithms are compared-implementation of a more complex algorithm is only warranted if it leads to a significant increase in warning time and accuracy of predicted ground shaking.

EEW-performance evaluation is evolving from proxy metrics, such as magnitude and location errors, to the actual target metric of EEW - predicted ground motion and its uncertainties. These ground-motion-based metrics help us answer these questions:

- How accurately can an EEW algorithm predict ground motions, and with what timeliness relative to the onset of strong ground motion?

- How does this accuracy translate into correct, false, and missed alerts in threshold-based end-user applications?

Additionally, a performance assessment might consider weighting the performance by the local population density within the alert region in addition to the accuracy of ground-motion estimates and warning times. Continuing research will assess how the ShakeAlert system performs using the developed metrics, identify deficiencies in current EEW approaches, and use these to prioritize further improvements to the system. Additionally, socialscience research assessing user needs and perception will drive development of improved performance metrics.

Realistic uncertainty measures should be determined that are consistent across all EEW algorithms. A shaking-intensity uncertainty is needed, as well as the likelihood that an alert constitutes a true event. These two uncertainty measures would capture both the historical performance of the EEW system as well as the information (for example, available data or quality of solution) from which the current alert is derived; these uncertainties must be combined and provided to technical users along with the alert for use in decision-making to initiate mitigating actions. 


\section{Public Alert Messaging}

Before an EEW system is used to issue public alerts, it is necessary to understand expectations from the public and to produce appropriate training material that maximize users' understanding and effective use of the alerts (Kamigaichi and others, 2009). The relatively low seismicity rates along the West Coast compared to other nation's regions with EEW systems mean that first-time public users in the United States will likely have limited, if any, experience of what "strong" ground shaking feels like and how EEW works.

Investigating user needs and expectations of an EEW system is critical to the success of ShakeAlert. We do have some information about the needs of users from several studies conducted around the world. For example, several alerts were issued by Mexico's EEW system (SASMEX; Espinosa-Aranda and others, 1995) in September 2017, including for the 2017 M7.1 Puebla earthquake that caused significant damage in Mexico City. In October 2017, a reconnaissance team of seismologists and social scientists examined public perception of the Mexico EEW system (Allen and others, 2017). Their findings suggest that alerts for incoming shaking should be simple and only provide information that is immediately actionable, for example, a message like "earthquake shaking expected"; however, initial alert information should be followed rapidly by information about the earthquake that occurred and post-event actions that users might take. Additionally, follow-up messages should declare an alert as false (if it was) to minimize confusion. We must also consider what follow-up messaging is necessary for cases where an alert is not issued for an earthquake that the system was designed to detect, or for regions that may have not have received a timely alert prior to strong shaking. In a study of early ShakeAlert users in California (Johnson and others, 2016), most technical users plan to provide warnings to individuals (employees and [or] customers) rather than activate automated responses to reduce damage to equipment or other infrastructure. More information about users' needs is necessary, but these studies point to the importance of investigating the appropriate alert thresholds, alert messaging, and technology pathways for rapid alert dissemination.

We must provide public users with enough information to know how to react before, during, and after an EEW alert. Advance education should include information about size of earthquakes and range of ground-shaking levels for which the system is designed to issue alerts. Additionally, it is critical to convey that a user may not always receive a timely warning or that they may receive a false alert (for example, an alert with no associated earthquake). The alert message itself must provide sufficient information to ensure understanding of the hazard and to encourage appropriate action. Rapid follow-up information may include how long to shelter after the alert has been received; this is especially true if a user does not feel ground shaking at their location. And, if shaking is strong, follow-up messages could provide information about expected aftershock information and (or) steps to take in the period immediately following the earthquake. The need to optimize the messaging is a reason why ShakeAlert needs to investigate end-user/public messaging. User messaging should be paired with new earthquake information and response products that could potentially help save lives and guide emergency response immediately after a large earthquake. Some of these new products are described in the section titled "Integrating ShakeAlert and Real-Time Earthquake Information Products" below. Some efforts may require coordination with other emergency management agencies (for example, Federal Emergency Management Agency and [or] State and local emergency-management agencies) to deliver public safety information, such as a response checklist with information about keeping phone lines free and stopping gas leaks, customized according to the user's location and earthquake shaking intensity and impact.

The ShakeAlert education and training is being developed by the Joint Committee on Communication, Education, and Outreach (JCCEO), a committee comprised of communications experts at USGS and partner universities as well as emergency managers in California, Oregon, and Washington. The JCCEO is currently developing a roadmap for implementation of a comprehensive and actionable training program for all audiences that integrates best practices from social-science research on hazard communications. This plan may need to consider potential differences between areas where alerts are distributed, such as a community's perception of their seismic risk and (or) how often alerts are expected to be issued. It will also need to develop best practices for training various groups and communicating early warning to various communities, sectors, and a broad audience with diverse needs.

\section{Technical User Needs and Development of a Cost-Benefit Framework}

To date, technical users are engaged through personto-person communication along the West Coast through the ShakeAlert JCCEO. A portal is available for technical users to request new alert capabilities and submit reports of technical problems. ShakeAlert should undertake regular (annual or bi-annual) feedback surveys of technical users and analyze the results to determine whether or not alert information aligns with user needs and to update performance metrics so that the system is evaluated (and improvements prioritized) based on maximizing user benefits. Surveys from other countries with EEW systems have provided information to guide future developments (Suárez and others, 2009; Nakamura and others, 2013). The user-feedback surveys should be augmented by workshops for technical users within different industry sectors (for example, transportation, emergency management, communications, and so forth), where key stakeholders can discuss new advances in ShakeAlert science as well as their specific needs. A framework for collecting feedback from these workshops, extracting common areas of concern, and integrating the highest priority items into the ShakeAlert project-management plan will need to be formalized. 
Technical users must also be trained to understand how to maximize their benefits from the EEW system. The goal of this work is to give users a basic framework to undertake specific cost-benefit actions for their organization in order to determine whether and how to utilize EEW alerts. The utility of an EEW system requires consideration of the expected performance of the ShakeAlert system, the expected distribution of earthquakes, a user's alerting and damage thresholds, and the required time for completing the mitigating action. This may require developing, in a generalized sense, user-specific cost functions for both the mitigating actions and amount of damage prevented. For example, ground-motion cost-based performance metrics could be applied to analyze the utility of EEW for various damage and alerting thresholds and for a range of expected earthquake ruptures, such as provided by the Uniform California Earthquake Rupture Forecast probabilities (Field and others, 2014) or similar studies.

\section{Alert Dissemination Technologies}

Currently, the ShakeAlert system distributes an XMLformatted alert message via public Internet to a limited set of beta and pilot users. These users utilize ShakeAlert products via direct access to XML messages, or through use of computer or mobile applications that parse and display information contained in the XML messages. For automated response, these users typically want a direct connection to the XML-formatted alert messages that are disseminated via public Internet by the ShakeAlert servers. For alerting to individuals, ShakeAlert currently provides a demonstration computer application (UserDisplay) and a mobile phone application (MyEEW) that parse the XML messages and display alert information. So far, these Internet-push distribution methods are limited in the number and types of people they can reach and are therefore not sufficient for broad dissemination of alerts. However, UserDisplay may have a role to play in providing a comprehensive view of system information to technical users and key stakeholders. Research is needed to understand the needs of technical user groups to drive future development of the UserDisplay program and extrapolate what other users want beyond what is currently provided by UserDisplay to inform future design choices.

Once public alerting is initiated, alerts must be efficiently disseminated to the public with minimal delays to ensure alerts get to people who need them; thus, the mechanisms by which ShakeAlert distributes products must be adapted and expanded. The ability to deliver alerts in a timely manner, release users after the warning has expired, and provide follow-up information explaining why the user did or did not receive an alert are all important to both the actual and perceived success of ShakeAlert. Research evaluating the alert latencies for current and developing distribution technologies is necessary; the results of this research will need to be regularly communicated to the JCCEO to guide ShakeAlert outreach. The single most important component of this task is to determine how ShakeAlert can distribute the information required for successful EEW alerting in a manner that is timely, scalable to millions of people, and robust during and following large earthquakes. Based on these results, we will need rapid internal technical development to implement the recommendations, and work closely with the JCCEO to educate the public on the types of information they should expect from ShakeAlert. While immediate large-scale activity is required to design and implement alerting technology for ShakeAlert before public rollout, it is important to recognize that this is not a one-time effort. As technology evolves and the ways people receive information changes, ShakeAlert will need to continuously reevaluate how it distributes alerts.

\section{Evolution of Alert Information and Messaging}

The planned EEW alert product is simple and conveys that earthquake shaking above a minimum threshold is expected in a region. Through feedback collected from users, we may learn that additional alert information would be beneficial. For example, users may want to know the peak amplitude of the shaking and (or) the expected arrival time for a given threshold of shaking at their location. Further, the duration over which ground motion exceeds a certain threshold is important for damage generation (for example, Nakamura and others, 2011) and for how shaking is perceived. Research is needed to explore whether existing or new methods could provide such information and what the expected uncertainties are on additional information. In addition, optimal EEWmessaging strategies for delivering more complex information will need to be developed. Examples include messages such as "expect shaking to continue for more than 10 seconds", or sending an "event over" message based on the expected duration. Sending an "event over" message might also provide an opportunity to share subsequent information about the likelihood of aftershocks to better prepare people for what is likely to follow a large-magnitude event.

\section{Integrating ShakeAlert and Real-Time Earthquake Information Products}

Development of new science products that use information from ShakeAlert may be possible. For example, rapid magnitude estimates, finite-fault locations, and (or) surface-slip estimates could potentially be used to estimate surface displacement at critical lifeline infrastructure, create maps of real-time peak-ground shaking, improve tsunami warning, and forecast aftershock probabilities. These products should be driven by priorities identified from user and stakeholder feedback and will require development of new methodologies, testing, and eventual implementation of each new operational product. Each potential product requires a proof-of-concept demonstration and assessments by relevant users before evolving into an operational product through comprehensive testing and software-engineering support. 


\section{Challenge 2-Make Alerts as Fast and Accurate as Possible}

The quality of real-time ground motion warnings may vary significantly over time; quality may increase as more data become available upon which warnings can be based, but it may also decrease if an earthquake grows into a more complex event for which ground motion is difficult to predict until the earthquake fault rupture has grown to sufficient size. Depending on the EEW alert distribution pathway, the frequency at which updates can be delivered to users is expected to vary and is as yet unknown. It may take several seconds to distribute EEW alerts across a large region, possibly hindering the speed with which updates can be sent. And it is likely that different user groups may require diverse types of alert information, such as expected shaking intensities versus peak ground acceleration or spectral amplitudes, as seen with the Japanese warning system (Fujinawa and Noda, 2013).

The goal of EEW system design is to maximize the warning accuracy and timeliness at any given point in time, such that the most accurate ground-motion estimates are provided with maximum time before the arrival of shaking that exceeds a given ground-motion threshold. How EEW quality can be maximized may depend on the size of the target earthquake: for medium-size events (M5-7), algorithms can be relatively simple but need to be fast, because affected regions are close to the epicenter, whereas very large events $(M 7+)$ require more complex algorithms that can characterize effects on ground motions from long earthquake fault ruptures in real time. It is these largest earthquakes for which real-time geodetic data, for example, from high-rate scientific GNSS stations, have the most potential for earthquake sourcebased algorithms to improve EEW because of the tendency of earthquake-magnitude estimates from the initial $\mathrm{P}$ wave to saturate for $M \geq 6.5$ (Kanamori, 2005; Rydelek and Horiuchi, 2006; Hoshiba and others, 2011). EEW systems must be able to provide accurate warnings across the expected range of magnitudes, earthquake fault-rupture lengths, locations, and earthquake-source types (focal mechanisms, directivities, and fault slip) that produce damaging ground motions within the alert region.

In the context of this challenge, we suggest how the quality of EEW ground-motion predictions can be evaluated and outline strategies that have the potential to increase EEW quality for different kinds of scenarios. The key areas that need to be addressed are:

- Improved ground-motion predictions;

- Improved identification of seismic phases in seismograms;

- Development of ground-motion-based EEW alert methods;

- Increased quality of earthquake point-source algorithm predictions;

- Increased quality of earthquake finite-fault algorithm predictions; and
- Propagation of uncertainties and development of a Bayesian framework.

\section{Improved Ground-Motion Predictions}

The EEW system is inherently a ground-motion warning system - users care about the level of shaking they experience at their location. For algorithms that only provide an estimate of an earthquake magnitude and location, the expected ground motions must be estimated by using a ground-motion prediction equation. However, the method of simply applying an existing ground-motion prediction equation (GMPE) to an earthquake magnitude and location results in large inherent uncertainties in EEW ground-motion predictions at the user's location (Allen, 2007). The choice of ground-motion models (GMPEs, ground motion to intensity conversion equations [GMICEs], and intensity prediction equations [IPEs]) is a crucial element in EEW systems, and there is room for improvement. The quality metrics suggested earlier will allow evaluation of which ground-motion models leads to the strongest EEW performance.

Most existing ground-motion models have not been specifically designed for EEW applications, and they are often dominated by recordings made at distances of tens to a few hundred kilometers from earthquake-generating faults. Many GMPEs also include parameters not readily available in real time or are not modeled in EEW algorithms. For example, most GMPEs use the earthquake depth as a model parameter (for example, Abrahamson and others, 2014), as it is a major predictor of the energetics of the earthquake and, hence, observed ground motion, yet current ShakeAlert point-source algorithms use a fixed depth for all earthquakes. Consideration of the depth or making an adjustment when it is not known is critical for accurately predicting the ground motions. Additionally, most existing GMPEs and IPEs use rupture distance, not epicentral/hypocentral distance (for example, Abrahamson and others, 2014; Boore and others, 2014) as the most meaningful source-to-receiver distance metric; yet, rupture-distance estimates for large earthquakes often only become available late in an EEW sequence when a finite-fault EEW algorithm comes into play. The ShakeAlert community should assess the potential performance improvements of using EEW-specific ground-motion models or the adaptation/optimization of existing relations. All ground-motion prediction models express strong variability of observed ground motion owing to variations in earthquake source parameters, seismic-wave propagation, and local site effects near the Earth's surface; these uncertainties should be included both in determining optimal alert criteria and in communicating expected system performance to users.

Implementing specific source, site, or seismic-wave propagation path components into early warning GMPEs will reduce the uncertainty in ground-motion estimation, yet necessarily lead to increased complexity and computational time associated with these improvements. For example, 
including a source-specific term, akin to an earthquakeenergy stress drop or earthquake-magnitude adjustment, can reduce the uncertainty in the ground-motion prediction. Also, including finite-fault information, particularly for large-earthquake fault ruptures, will lead to more accurate near-field ground-motion prediction, which is of particular importance for EEW. The addition of wave-propagation directivity information as the rupture unfolds could improve our ground-motion accuracy, but may prove to be challenging. Additionally, we need to consider how to incorporate site parameters (for example, $V_{\mathrm{S} 30}$, the shear-wave velocity in the upper 30 meters of Earth's crust) or basin characterization in EEW to reduce uncertainties in ground-motion estimates. It is also important to consider how to best adapt current engineering-oriented GMPEs, which often include sophisticated terms that are typically not immediately known in an early warning situation, such as the differences in ground shaking on the upper versus lower sides of a dipping fault, known as the hanging-wall effect.

\section{Improved Identification of Seismic Phases in Seismograms}

In the current ShakeAlert system, EEW alerts using point-source algorithms are based on P-wave detections at a small number of seismic stations (Kohler and others, 2018). Therefore, EEW system performance can be enhanced by refining our ability to distinguish P-wave energy on seismic waveforms from all other sources of motion. Algorithms currently use a variety of waveform characteristics, but better approaches are needed.

The ShakeAlert algorithm uses a combination of methods to distinguish local events from regional or teleseismic earthquakes including filtering based on characteristic or peak period parameter and peak-displacement amplitude, setting minimum thresholds for different parameters, and requiring multiple stations to confirm events (Allen and Kanamori, 2003; Allen, 2007; Wu and others, 2007; Allen and others, 2009; Böse and others, 2009; Kuyuk and Allen, 2013; Hartog and others, 2016). A number of measures are used to distinguish earthquake signals from noise, but these methods occasionally admit environmental noise or teleseismic signals, or reject true earthquake arrivals (Hartog and others, 2016; Cochran and others, 2018). Further research aimed at noise discrimination at the single-station level is needed. Methods may include using either parametric information (for example, consistency of multiple waveform attributes such as peak ground motions, frequency content, and so forth) or machinelearning techniques to automatically categorize waveforms as local seismic phases or noise (for example, Ross and others, 2018), to decrease alerting time by placing greater confidence in the earliest alerts, as well as to reduce false and missed earthquakes. The machine-learning techniques may require use of graphics processing units within a cloud that provides computing resources on demand.

Future EEW software codes may require serverless architecture for improved performance in a cloud computational facility, which would enable the use of opensource software tools for a variety of routine tasks. Testing and developing EEW algorithms as a platform using modern software frameworks will enable EEW capacity to evolve with other emerging technologies. This is necessary to facilitate interoperability between EEW and emerging data communications and automatic decision tools deployed by our most sophisticated EEW users.

The current point-source ShakeAlert algorithm requires phase discrimination so that only $\mathrm{P}$-wave information is used and $\mathrm{S}$ waves are excluded. If S-wave detections are not correctly discarded, magnitude and location estimates may be erroneous and split-event alerts can occur. Split events are multiple alerts issued for a single event that are based on poor location and magnitude estimates (Hartog and others, 2016; Cochran and others, 2018). Alternatively, when P-wave detections are incorrectly discarded, earthquake alerts have been delayed, degraded, or prevented (Hartog and others, 2016). Current methods do not ideally distinguish between Pand S-wave phases. While there is ongoing research focused on using polarization analysis for $\mathrm{P}$ - and S-wave phase discrimination, additional techniques should be explored.

\section{Development of Ground-Motion-Based Alert Methods}

Ground-motion-based EEW alerting methods (for example, Hoshiba, 2013; Hoshiba and Aoki, 2015; Kodera and others, 2016; Yang and others, 2018) may provide rapid warnings for moderate to strong ground shaking and may have improved performance during aftershock sequences or other periods of high seismicity rates. The method deployed in Japan (Kodera and others, 2018) is straightforward: if strong ground motions are observed at a seismic station, an alert is immediately issued to all locations within $\sim 30 \mathrm{~km}$ of that station, warning those regions to expect similar shaking levels. The approach may improve the accuracy of the ground-motion prediction relative to source-parameter-based approaches by automatically adjusting the median prediction to account for between-earthquake variability of ground motion (that is, the "event term" in GMPEs). Furthermore, ground-motionbased EEW methods are less likely to be confused at times when multiple earthquakes occur nearly simultaneously, such as during aftershock sequences (Kodera and others, 2018); they also may not suffer from the same failure modes of earthquake source-based methods, including split events and teleseisms mischaracterized as local earthquakes. Finally, the method is attractive for use with low-cost seismic sensors that can provide dense observations of PGA and PGV (Kodera and others, 2016). This method may be extended to include basic attenuation functions to estimate 
expected ground motions at greater distances from the source. Further research is needed on ground-motion-based methods, including quantitative evaluation of potential gains in accuracy and timing of ground-motion warnings in comparison to other methods under consideration for use in ShakeAlert.

\section{Increased Quality of Point-Source Algorithm Ground-Shaking Predictions}

A variety of strategies to improve point-source type EEW algorithm predictions have been proposed, but not all of them have been extensively tested or optimized based on ground-motionperformance metrics. Some of the strategies to consider are:

- Better location estimates using, for example, real-time seismic-phase detection and azimuth estimation;

- Configurable parameter measurement windows, including use of variable-length windows to estimate parameters such as peak displacement $(P \mathrm{~d})$ beyond their current limit (for example, 4 seconds);

- The use of station corrections that correct for local site effects to improve magnitude estimates;

- Frequency-dependent ground-motion predictions (for example, low-frequency ground-motion prediction for large buildings, such as spectral acceleration); and

- Denser stations/redundant data-more seismic stations (than the "target" 10- to 20-km spacing) may make the detection faster and more accurate. Designing an optimal station density requires knowledge of how station density changes the timeliness of alerts and the quality of the expected ground-motion estimates.

\section{Increased Quality of Finite-Fault Algorithm Predictions}

Finite-fault earthquake source algorithms will be most important for $M>7.0$ earthquakes and subduction zone earthquakes. How good and how timely are ground motion predictions at sites that are far away from the hypocenter, yet close to the earthquake fault-rupture plane?

Finite-fault methods that are currently under development involve both seismic and geodetic data. Seismic methods can identify regions in the near field of ruptures and track the evolving earthquake fault-rupture source (Böse and others, 2012; Böse and others, 2015; Böse and others, 2018). Through identification of the extent of the finite rupture, the predicted ground motions along an extended rupture are improved. Research is needed to understand how quickly the seismic-based algorithms identify significant finite-fault effects in the distribution of ground motion and optimize these methods to reduce latency and improve groundmotion predictions.

Large static offsets associated with fault slip during earthquake ruptures can be measured with geodetic instrumentation in real time. Several algorithms that use GNSS data, alone or in combination with seismic records, have been developed for potential EEW applications (Allen and Ziv, 2011; Grapenthin and others, 2014; Minson and others, 2014; Crowell and others, 2016). Initial testing of these approaches demonstrates that geodetic information can enable more accurate and rapid magnitude and finite-fault estimates that, in turn, might improve alert accuracy for large $(M>7.0)$ earthquakes. The scope of ShakeAlert products could also be expanded to include products that predict PGD and (or) peak dynamic strain (PDS). Quantitative evaluation of the tradeoff between accuracy and timeliness of shaking estimates derived from geodetically constrained source models, as well as the improvement to alerting offered by a joint seismic-geodetic system compared to a seismic-only system, is required in order to assess the value that geodetic data and methods would bring to the ShakeAlert system.

\section{Propagation of Uncertainties and Development of a Bayesian Framework}

Obtaining accurate and comparable estimates of uncertainties in source and (or) ground-motion information provided by each algorithm should be a priority. The relationship between the uncertainties must be compared with empirical uncertainties that can be evaluated with retrospective performance analysis of a large dataset to determine whether they agree. Also, analyses of how uncertainties change as an event evolves and more information becomes available are needed.

With accurate time-dependent uncertainties available for all algorithm components, the entire system could be placed into a Bayesian framework. One approach, built on a probabilistic decision module, considers the probabilities of predicted ground motions through comparisons to available observed ground motions (for example, Minson and others, 2017). The underlying logic of such a probabilistic decision module should be developed and tested to study how real-time groundmotion predictions from different algorithms are optimally combined to generate better ensemble estimates. It may also be possible to consider prior seismic information, such as the locations of recent seismicity (that are potentially foreshocks) and known active faults. As a further step, the EEW system can use Bayesian decision theory to calculate the cost/benefit of proposed actions in real time (Wu and others, 2013, 2014). Thus, it is important to not only test whether ShakeAlert is providing timely and accurate information about expected ground-shaking intensity, but whether this information is being presented in the appropriate cost-benefit framework to enable decisions about whether or not a user should take an action (for example, stopping trains, extinguishing open flames, and so forth). 


\section{Challenge 3-Ensure Reliability When It Counts}

ShakeAlert must perform well for large, potentially damaging earthquakes. The background rate of these events is once or twice per decade in the western continental United States, although such events are likely to cluster in mainshockaftershock sequences. A challenge for any EEW system is therefore to ensure the system's performance is optimal in the instant that such an event (or cluster of events) occurs, and does not degrade in what may be many years between such events. Development of robust historical datasets and scenario waveforms is critical for ShakeAlert. We also have not observed the full spectrum of earthquakes (or sources of noise) for which ShakeAlert must be ready along the West Coast, so we must work to develop a robust system capable of handling the unexpected. Assuring reliability when it counts is divided into the following broad topics:

- Appropriate historical datasets for system performance testing;

- Synthetic waveforms for performance testing and evaluation; and

- Expecting the unexpected.

\section{Appropriate Historical Datasets for System Performance Testing}

Verification of algorithm performance is needed to determine if ShakeAlert products meet performance standards. The Testing and Certification Platform was developed in order to test new versions of ShakeAlert algorithms and (or) new algorithms prior to deployment in the production system. Evaluation of algorithms is undertaken using a suite of previously recorded waveforms of historical earthquakes in California, Oregon, and Washington, as well as teleseismic, noisy, or anomalous waveforms that have caused (or may be expected to cause) the system to issue false alerts (Cochran and others, 2018). Current test suites that are used in performance testing are limited in the magnitude ranges and focus on individual events rather than longer time series; therefore, it is necessary to examine the composition of the test data to ensure accurate assessment of system performance under a variety of conditions. For example, to address the limited number of large earthquakes, it may be important to consider inclusion of locally recorded data from earthquakes from around the world, such as those recorded in Japan, Mexico, and Taiwan. However, it is necessary to understand how these data will translate into accurate representations of ShakeAlert performance by considering differences in station distributions, tectonic setting, ground-motion attenuation and amplification, and other factors. Furthermore, it remains an open question whether it is necessary for the magnitude distribution of such data to match Gutenberg-Richter statistics (Gutenberg and Richter, 1944) for an accurate assessment of system performance at different alert and damage thresholds.

\section{Synthetic Waveforms for Performance Testing and Evaluation}

Large earthquakes are few and far between. Thus, in order to assess the performance of the system we may need to consider the use of scenario events and waveforms. This is especially important for the geodetic components of the system, for which there are only limited data from historical events (Ruhl and others, 2017). The challenge with generating synthetic waveforms for EEW testing is that they must contain both high-frequency energy to trigger seismic algorithms and low-frequency energy for testing geodetic algorithms, as well as accurately producing both $\mathrm{P}$ and $\mathrm{S}$ waves.

There are now standard community hybrid methods for generating broadband $\mathrm{S}$ waves, which combine forward modeling (as much as $1 \mathrm{Hertz}, \mathrm{Hz}$ ) and stochastic signals at higher frequencies (for example, Boore, 2003). Methods have also been developed to produce synthetic displacement waveforms appropriate for testing geodetic algorithms (Melgar and others, 2016). However, existing geodetic algorithms are typically triggered by the seismic component of the system; ongoing research is focused on incorporating high frequencies into these synthetics (for example, Yamada and Heaton, 2008; Ruhl and others, 2017; Wirth and others, 2017). Ideally, we need thousands of realistic slip patterns for many magnitudes (M6-8 in California and M7-9.2 in Cascadia), and associated waveforms that trigger the seismic-based systems and provide realistic data to the geodetic ones. Through systematic testing with a large number of synthetic events, and including multiple realizations of the same scenario event, we will gain a thorough understanding of each EEW algorithm's strengths and weaknesses.

Testing protocols for validating scenario earthquakes and their resulting synthetic waveforms must also be established. Scenario earthquakes must obey realistic moment-release patterns as inferred from observations (for example, Melgar and Hayes, 2017; Ye and others, 2016). Whereas synthetic waveforms have been validated in terms of metrics useful to the engineering seismology community, such as peak motions (PGV, PGA, and spectral accelerations) (for example, Goulet and others, 2014), these metrics are predominantly sensitive to features of the $S$ waves and not the $\mathrm{P}$ waves. Minimal effort has been devoted to validating techniques for generating broadband synthetic waveforms for their use in testing EEW algorithms. Validation of existing suites of synthetic waveforms will help guide development of additional suites of earthquake scenarios and new techniques for generating synthetic waveforms.

\section{Expecting the Unexpected}

We must identify ways to expose ShakeAlert to unanticipated events, or scenarios that do not happen with 
sufficient regularity to be part of our current or historical testing. There is no simple solution to this problem, but there are opportunities to test ShakeAlert performance for an expanded range of events. We must also accept potential failure of the system owing to an unexpected or unprecedented event, and plan how to communicate information about such failures as rapidly as possible.

One approach is to expand the synthetic ground motions described above to simulate large events and complex sequences, including aftershock sequences, foreshockmainshock events, and large offshore events (including Cascadia subduction events). As mentioned above, synthetic data are required to have sufficient high-frequency content to be realistic for the seismic algorithms, while also having the low-frequency content (including permanent displacements) required for geodetic algorithms. One challenge to this approach is in defining, based on available computational resources or other considerations, a limited set of appropriate scenarios for which to produce deterministic simulations. One clear case is for tsunami earthquakes for which the high-frequency ground shaking may be relatively depleted compared to the longer period amplitudes. We must also ensure a sufficiently agile system for producing synthetics that can be altered to reflect the current station distribution (or even test future states).

As testing datasets grow in size, it is desirable to develop the capability to test both long, continuous waveform records as well as hundreds or thousands of earthquake records rapidly. Current capabilities are limited because events must be run at real-time speeds (for example, 7-minute-long event waveforms take 7 minutes to run through the test system). More efficient testing mechanisms will allow more tests to be run to determine, for example, the effects of noise and network topology changes. In order to evaluate the performance of updated versions of algorithms, or to test algorithms with new datasets, new replay tools have been developed. These programs make it possible to replay anything from a few recordings of a single event to several days of waveform data from an entire network at a time. As in the case of synthetic ground motions, being able to "tweak" replayed data would add value. For example, the ability to add certain types of noise (spikes, square wave pulses, and so forth) to test system response is desirable and should be pursued as a research avenue.

We also must explore different potential failure scenarios for ShakeAlert. How will the system handle cases of highaftershock activity during which the communications infrastructure for delivering alerts may become progressively degraded? What if an earthquake happens during or soon after another natural-disaster emergency, such as a wildfire or flood? How will the system respond to potential security threats? These types of events must be considered and guarded against as well, while also taking into consideration their relative likelihood of occurrence to ensure appropriate priority is given to understanding and addressing the most likely scenarios.

\section{Challenge 4-Explore the Use of New Instrumentation}

EEW is possible today owing to the combination of geophysical observational systems with processing algorithms that can characterize the expected ground shaking in real time. We have so far focused on the use of "traditional", that is, scientific-grade, seismic and geodetic instrumentation that has been the basis of most of the EEW development to date. The quality of ShakeAlert performance could be improved by adding more instrumentation of this traditional type; however, there is also the potential to make use of other and new types of instrumentation. The instrumentation and the associated methods described below are in various stages of design, development, and proof-of-concept. Thus, these do not provide an alternative to ShakeAlert's use of traditional networks. However, they do provide the potential to contribute to ShakeAlert in the future. We focus on several areas of interest:

- Low-cost instrumentation;

- Offshore instrumentation; and

- Strainmeters.

\section{Low-cost instrumentation}

One approach to improving the speed and accuracy of an EEW system in order to increase the area receiving actionable alerts and decrease the likelihood of false alarms is to increase the number of instruments close to an earthquake rupture. Given limited funds available for building and maintaining instrument networks, low-cost instruments may be an effective way of supplementing our higher quality traditional networks of instruments. Their efficacy for EEW depends on signaldetection characteristics and operational stability.

Microelectromechanical system (MEMS) accelerometers are the best studied and operationally proven type of low-cost sensor. The Quake Catcher Network (Cochran and others, 2009) and Community Seismic Network (Clayton and others, 2011) are operating networks of MEMS seismometers for seismic and engineering studies. These sensors have been benchmarked against traditional seismometers (Cochran, and others, 2011; Evans, and others, 2014) and have been successfully used for event detection (for example, Chung and others, 2011; Lawrence and others, 2014; Chung and others, 2015). Mini-arrays of low-cost sensors may be able to extract higher order earthquake-source information than is available from a single 3-component instrument. By combining these low-cost devices with traditional seismometers, it may be possible to improve confidence in initial detections at modest cost, but much research is needed to explore the utility of these approaches. Further research is needed to understand the 
degree to which these low-cost networks may contribute to the ShakeAlert system in providing fast and reliable groundmotion alerts.

MEMS accelerometers are integrated into smartphones, allowing for the possibility of supplementing ShakeAlert with crowd-sourced observations (Finazzi and Fassò, 2017; Kong and others, 2016a). In the case of smartphones, the challenge is in harnessing the millions of privately owned phones. However, it has been proposed that crowd-sourced observations from smartphone MEMS accelerometers alone could be used to provide EEW. Two large-scale efforts are underway. The Earthquake Network application has been downloaded by several million users and has identified more than 780 earthquakes based on observing clusters of triggers on user's phones (Finazzi and Fassò, 2017; Finazzi, 2016). The MyShake application has been downloaded by more than 200,000 users worldwide and collects on-phone triggers and also waveform data (Kong and others, 2016b). MyShake is not yet issuing alerts, but it detects earthquakes and estimates earthquake locations and magnitudes in real time.

Low-cost, consumer-grade global positioning system (GPS) chips, including those found in smartphones, are capable of recording displacements as small as those observed in a M6 earthquake (Minson and others, 2015). While these consumer-grade GPS solutions are noisier than their scientificgrade counterparts, they have several attractive characteristics besides their low cost. Specifically, they use on-board positioning and can obtain real-time correction information from satellite-based augmentation systems, both of which only the most advanced (and typically most expensive) scientific GPS receivers can do. Consumer GPS sensors eliminate significant latencies and vulnerabilities found in many scientific GPS network precise-point positioning operations. For example, correction information can be obtained from a satellite constellation rather than an Internet connection (that may be unavailable during and after a significant earthquake), and a sensor's position can be computed on the GPS chip instead of sending the raw observations to a processing center.

\section{Offshore Instrumentation}

The plate boundary along western North America includes convergent systems offshore northern California, Oregon, Washington, and Alaska. Subduction zones present a different set of challenges compared to the strike-slip San Andreas Fault System. In subduction environments, the source region for large earthquakes is often located outside the footprint of regional seismic networks. It takes time for the first seismic waves from offshore earthquakes to arrive onshore, delaying characterization of the earthquake, although the arrival of strong shaking is likewise delayed. It is also critical to correctly discriminate outer-rise and in-slab earthquakes from megathrust events, which carry significantly greater seismic and tsunami hazard.

For Cascadia, the offshore environment is currently monitored by the Regional Scale Nodes offshore Oregon and the NEPTUNE Ocean Observatory offshore Vancouver Island. Continuous seismic data are telemetered in near real time to the Pacific Northwest Seismic Network from 14 ocean-bottom seismometers (OBS) offshore Oregon in two dense clusters and the data are ingested into ShakeAlert. However, currently these data typically do not contribute to ShakeAlert owing to telemetry latency. Ocean Networks Canada is currently exploring how they might adapt their existing offshore instrumentation to provide early warning for British Columbia.

Ideally, a real-time, offshore network would be based on deploying a seafloor cable that would provide power and telemetry to seafloor instruments. A range of instruments could be deployed on the ocean floor for real-time monitoring. The most useful instruments would be OBS that record passing seismic waves and bottom-pressure recorders that record changes in water pressure related to vertical movement of the seafloor. GPS-acoustic systems (wherein a sea-floor benchmark is acoustically coupled to a floating GPS-enabled buoy or robotic sea-surface vessel) would be the best means to measure horizontal displacement. However, the wide spacing of seafloor transponders and continuously operating seasurface platform needed make this approach more challenging for real-time applications, although seafloor-based geodetic measurements to rapidly estimate seafloor deformation would be particularly useful for EEW coupled to tsunami early warning.

Seafloor instrumentation is an active area of development from which ShakeAlert could benefit in the future. It is possible that flow meters measuring changes in fluid flux may provide information about changes in shallow strain. Other emergent technologies include fiber-optic strainmeters or acoustic-mesh networks. However, these new data sources will require new, or modified, detection methods as they will contain different types of noise than is typical for land-based seismic or GNSS stations.

\section{Strainmeters}

An accurate estimate of an earthquake's moment release naturally depends on detection of the associated static and dynamic deformation, preferably as close to the fault as possible. Although traditional seismometers measure inertial quantities, like acceleration, and continuous-GPS stations measure ground displacement very well, these quantities alone do not capture the full broadband-frequency content of ground deformation except when combined appropriately (Melgar and others, 2013). Geodetic-grade strainmeters can measure elastodynamic deformation associated with earthquakes over a broad frequency band, ranging from static values to a high-frequency limit imposed by their baseline lengths; their seismic detection characteristics complement traditional instrumentation (Barbour and Agnew, 2012).

Currently, 33 of the 82 borehole strainmeters (BSM) in the Plate Boundary Observatory (PBO) are located within $275 \mathrm{~km}$ of the Cascadia subduction zone trench axis, where increased station density (whether seismic or geodetic) is 
critical to fully characterizing large megathrust events. Recent developments in fiber-optic strain-sensing systems suggest that a dense network of direct measurements of strain can be made efficiently and affordably, either in boreholes (for example, DeWolf and others, 2015) or by utilizing existing telecommunications infrastructure (for example, Lindsey and others, 2017). Other BSM networks exist in the United States outside of PBO - most notably the USGS network in the San Francisco Bay area and elsewhere along the North AmericanPacific Plate margin.

Barbour and Crowell (2017) have investigated the feasibility of using BSM observations from the PBO network to rapidly determine earthquake magnitude. They found a simple log-log scaling between earthquake magnitude, peak root-mean-squared strain, and hypocentral distance that one could use to estimate magnitude rapidly, with a standard error of 0.3 magnitude units. This strain scaling is also in agreement with GPS-derived strains in triangulated subnetworks for the 2011 moment magnitude $\left(M_{\mathrm{w}}\right) 9.0$ Tohoku-oki earthquake when spatial aliasing is taken into account. Furthermore, the greatest source of bias in the regression is found to be event source and seismic-wave-propagation path terms owing to large-scale geologic heterogeneities, and rock materialvelocity contrasts or fault-frictional variations, rather than local site or station terms, owing to variability in installation techniques or local geology.

The results of Barbour and Crowell (2017) for the PBO BSMs were found using raw, uncalibrated, instrumental strain observations, indicating the ease of potential inclusion into EEW systems. Moreover, accurate estimates of magnitude can be made even when a single strain channel (out of four) is functional because their observation is not based on calibrated tensor-strain quantities that require at least three operational channels; this extends the potential lifespan of the PBO BSMs well beyond their nominal lifespan for tensor-strain estimation (for example, detection of slow slip). Strain observations, particularly attenuation with distance, are consistent with the peak ground-velocity data used to create the USGS ShakeMap, and show no systematic differences between the types of strainmeters: Sacks-Evertson dilatometers, SacksEvertson-Sakata 3-component extensometers, and Gladwin 4-component extensometers (Barbour and Langbein, 2018). Additional research is needed to quantify the contribution of strainmeter data to improving the timeliness and (or) accuracy of ground-motion predictions by the ShakeAlert system.

\section{Conclusions}

This document attempts to capture the range of research needs and opportunities that should be addressed over the next 5 years to improve the accuracy, timeliness, and usefulness of ShakeAlert products. The many wide-ranging approaches documented here are testament to the creativity of the large numbers of researchers now actively engaged in the development effort. The United States is poised to launch a public warning system to alert communities of incoming earthquake shaking that is a product of vigorous and diverse research efforts at multiple public and private institutions and conducted within a collaborative framework. It is key that we maintain this diversity of research and collaborative team effort to ensure the success of the first earthquake early warning system in the United States.

\section{References Cited}

Abrahamson, N.A., Silva, W.J., and Kamai, R., 2014, Summary of the ASK14 Ground Motion Relation for Active Crustal Regions: Earthquake Spectra, v. 30, no. 3, p. 1025-1055, https://doi.org/10.1193/070913EQS198M.

Allen, R.M., 2007, The ElarmS earthquake warning methodology and application across California in Gasparini, P., Manfredi, G, and J. Zschau (eds.), Seismic Early Warning: Springer, New York, p. 21-44.

Allen, R.M., Cochran, E.S., Huggins, T., Miles, S., and Otegui, D., 2017, Quake warnings, seismic culture: Science, v. 358 , no. 6367 , p. 1111 , https://doi.org/10.1126/science. aar4640.

Allen, R.M., Gasparini, P., Kamigaichi, O., and Böse, M., 2009, The status of earthquake early warning around the world - An introductory overview: Seismological Research Letters, v. 80, no. 5, p. 682-693, https://doi.org/10.1785/ gssrl.80.5.682.

Allen, R.M., and Kanamori, H., 2003, The potential for earthquake early warning in southern California: Science, v. 300, p. 786-789, https://doi.org/10.1126/science.1080912.

Allen, R.M., and Ziv, A., 2011, Application of real-time GPS to earthquake early warning: Geophysical Research Letters, v. 38, no. 16, 7 p., https://doi.org/10.1029/2011GL047947.

Barbour, A.J., and Agnew, D.C., 2012, Detection of Seismic Signals Using Seismometers and Strainmeters: Bulletin of the Seismological Society of America, v. 102, no. 6, p. 2484-2490, https://doi.org/10.1785/0120110298.

Barbour, A.J., and Crowell, B.W., 2017, Dynamic Strains for Earthquake Source Characterization: Seismological Research Letters, v. 88, no. 2A, p. 354-370, https://doi. org/10.1785/0220160155.

Barbour, A.J., and Langbein, J.O., 2018, Near-source attenuation of strains from the 2018 M4.4 Berkeley earthquake [abs.]: Broomfield, Colo., UNAVCO Science Workshop, $1 \mathrm{p}$.

Boore, D.M., 2003, Simulation of ground motion using the stochastic method: Pure and Applied Geophysics, v. 160, no. 3-4, p. 635-676, https://doi.org/10.1007/PL00012553. 
Boore, D.M., Stewart, J.P., Seyhan, E., and Atkinson, G.M., 2014, NGA-West 2 equations for predicting PGA, PGV, and 5\% Damped PSA for shallow crustal earthquakes: Earthquake Spectra, v. 30, no. 3, p. 1057-1085, https://doi. org/10.1193/070113EQS184M.

Böse, M., Felizardo, C., and Heaton, T., 2015, Finitefault rupture detector (FinDer) - Going real-time in Californian ShakeAlert warning system: Seismological Research Letters, v. 86, no. 6, p. 1692-1704, https://doi. org/10.1785/0220150154.

Böse, M., Hauksson, E., Solanki, K., Kanamori, H., Wu, Y-M., and Heaton, T., 2009, A new trigger criterion for improved real-time performance of onsite earthquake early warning in southern California: Bulletin of the Seismological Society of America, v. 99, no. 2A, p. 897-905, https://doi. org/10.1785/0120080034.

Böse, M., Heaton, T., and Hauksson, E., 2012, Real-time finite fault rupture detector (FinDer) for large earthquakes: Geophysical Journal International, v. 191, no. 2, p. 803-812, https://doi.org/10.1111/j.1365-246X.2012.05657.x.

Böse, M., Smith, D.E., Felizardo, C., Meier, M-A., Heaton, T.H., and Clinton, J.F., 2018, FinDer v.2-Improved real-time ground-motion predictions for M2-M9 with seismic finitesource characterization: Geophysical Journal International, v. 212, no. 1, p. 725-742, https://doi.org/10.1093/gji/ggx430.

Chung, A.I., Cochran, E.S., Kaiser, A.E., Christensen, C.M., Yildirim, B., and Lawrence, J.F., 2015, Improved rapid magnitude estimation for a community-based, low-cost MEMS accelerometer network: Bulletin of the Seismological Society of America, v. 105, no. 3, p. 1314-1323, https://doi. org/10.1785/0120140232.

Chung, A.I., Neighbors, C.J., Belmonte, A., Miller, M., Sepulveda, H.H., Christensen, C., Jakka, R., Cochran, E.S., and Lawrence, J.F., 2011, The Quake-Catcher Network Rapid Aftershock Mobilization Program Following the 2010 M8.8 Maule, Chile Earthquake: Seismological Research Letters, v. 82, p. 526-532, https://doi.org/10.1785/gssrl.82.4.526.

Clayton, R.W., Heaton, T., Chandy, M., Krause, A., Kohler, M., Bunn, J., Guy, R., Olson, M., Faulkner, M., Cheng, M-H., Strand, L., Chandy, R., Obenshain, D., Liu, A., and Aivazis, M., 2011, Community seismic network: Annals of Geophysics, v. 54, no. 6, p. 738-747, https://doi.org/10.4401/ ag-5269.

Cochran, E.S., Lawrence, J.F., Christensen, C., and Jakka, R.S., 2009, The Quake-Catcher Network-Citizen science expanding seismic horizons: Seismological Research Letters, v. 80, no. 1, p. 26-30, https://doi.org/10.1785/gssrl.80.1.26.
Cochran, E.S., Lawrence, J.F., Kaiser, A., Fry, B., Chung, A., and Christensen, C., 2011, Comparison between low-cost and traditional MEMS accelerometers - A case study from the M7.1 Darfield, New Zealand aftershock deployment: Annals of Geophysics, v. 54, no. 6, p. 728-737, https://doi. org/10.4401/ag-5268.

Cochran, E.S., Kohler, M.D., Given, D., Guiwits, S., Meier, M-A., Ahmand, M., Henson, I., Andrews, J., and Hartog, J.R., 2018, Earthquake early warning ShakeAlert system - Testing and certification platform: Seismological Research Letters, v. 89, no. 1, p. 108-117, https://doi.org/10.1785/0220170138.

Crowell, B.W., Schmidt, D.A., Bodin, P., Vidale, J.E., Gomberg, J., Hartog, J.R., Kress, V.C., Melbourne, T.I., Santillan, M., Minson, S.E., and Jamison, D.G., 2016, Demonstration of the Cascadia G-FAST geodetic earthquake early warning system for the Nisqually, Washington earthquake: Seismological Research Letters, v. 87, no. 4, p. 930-943, https://doi. org/10.1785/0220150255.

DeWolf, S., Wyatt, F.K., Zumberge, M.A., and Hatfield, W., 2015, Improved vertical optical fiber borehole strainmeter design for measuring Earth strain: Review of Scientific Instruments, v. 86, no. 11, p. 114502, https://doi.org/10.1063/1.4935923.

Espinosa-Aranda, J.M., Jiménez, A., Ibarrola, G., Alcantar, F., Aguilar, A., Inostroza, M., Maldonado, S., 1995, Mexico City Seismic Alert System: Seismological Research Letters, v. 66, no. 6, p. 42-53, https://doi.org/10.1785/gssrl.66.6.42.

Evans, J.R., Allen, R.M., Chung, A.I., Cochran, E.S., Guy, R., Hellweg, M., Lawrence, J.F., 2014, Performance of Several Low-Cost Accelerometers: Seismological Research Letters, v. 85, no. 1, p. 147-158, https://doi.org/10.1785/0220130091.

Field, E.H., Arrowsmith, R.J., Biasi, G.P., Bird, P., Dawson, T.E., Felzer, K.R., Jackson, D.D., Johnson, K.M., Jordan, T.H., Madden, C., Michael, A.J., Milner, K.R., Page, M.T., Parsons, T., Powers, P.M., Shaw, B.E., Thatcher, W.R., Weldon, R.J., II, and Zeng, Y., 2014, Uniform California Earthquake Rupture Forecast, Version 3 (UCERF3)-The time-independent model: Bulletin of the Seismological Society of America, v. 104, no. 3, p. 1122-1180, https://doi.org/10.1785/0120130164.

Finazzi, F., 2016, The Earthquake Network Project-Toward a crowdsourced smartphone-based earthquake early warning system: Bulletin of the Seismological Society of America, v. 106, no. 3, p. 1088-1099, https://doi.org/10.1785/0120150354.

Finazzi, F., and Fassò, A., 2017, A statistical approach to crowdsourced smartphone-based earthquake early warning systems: Stochastic Environmental Research and Risk Assessment, v. 31, no. 7, p. 1649-1658, https://doi.org/10.1007/ s00477-016-1240-8. 
Fujinawa, Y., and Noda, Y., 2013, Japan's earthquake early warning system on 11 March 2011-Performance, shortcomings, and changes: Earthquake Spectra, v. 29, no. S1, p. S341-S368, https://doi.org/10.1193/1.4000127.

Given, D.D., Cochran, S.E., Heaton, T., Hauksson, E., Allen, R., Hellweg, P., Vidale, J., and Bodin, P., 2014, Technical implementation plan for the ShakeAlert production systemAn earthquake early warning system for the West Coast of the United States, U.S. Geological Survey Open-File Report 2014-1097, 25 p., https://dx.doi.org/10.3133/ofr20141097.

Goulet, C.A., Abrahamson, N.A., Somerville, P.G., and Woodell, K.E., 2014, The SCEC Broadband Platform validation exercise-Methodology for code validation in the context of seismic-hazard analyses: Seismological Research Letters, v. 86, no. 1, p. 17-26, https://doi.org/10.1785/0220140104.

Grapenthin, R., Johanson, I.A., and Allen, R., 2014, Operational real-time GPS-enhanced earthquake early warning: Journal of Geophysical Research, v. 119, https://doi. org/10.1002/2014JB011400.

Gutenberg, B. and Richter, C.F., 1944, Frequency of earthquakes in California: Bulletin of the Seismological Society of America, v. 34, no. 4, p. 185-188.

Hartog, J.R., Kress, V.C., Malone, S.D., Bodin, P., Vidale, J.E., and Crowell, B.W., 2016, Earthquake early warning-ShakeAlert in the Pacific Northwest: Bulletin of the Seismological Society of America, v. 106, no. 4, p. 1875-1876, https://doi. org/10.1785/0120150261.

Hoshiba, M., 2013, Real-time prediction of ground motion by Kirchhoff-Fresnel boundary integral equation method: Extended front detection method for earthquake early warning: Journal of Geophysical Research, v. 118, p. 1038-1050, https:// doi.org/10.1002/jgrb.50119.

Hoshiba, M., and Aoki, S., 2015, Numerical shake prediction for earthquake early warning - Data assimilation, real-time shake mapping, and simulation of wave propagation: Bulletin of the Seismological Society of America, v. 105, no. 3, p. 1324-1338, https://doi.org/10.1785/0120140280.

Hoshiba, M., Iwakiri, K., Hayashimoto, N., Shimoyama, T., Hirano, K., Yamada, Y., Ishigaki, Y., and Kikuta, H., 2011, Outline of the 2011 off the Pacific coast of Tohoku earthquake $\left(\mathrm{M}_{\mathrm{w}}\right.$ 9.0) - Earthquake early warning and observed seismic intensity: Earth, Planets, and Space, v. 63, no. 7, p. 547-551, https://doi.org/10.5047/eps.2011.05.031.

Hoshiba, M., Kamigaichi, O., Saito, M., Tsukada, S., and Hamada, N., 2008, Earthquake early warning starts nationwide in Japan: Eos, v. 89, no. 8, p. 73-74.
Johnson, L.A., Rabinovici, S., Kang, G.S., and Mahin, S.A., 2016, California Earthquake Early Warning System Benefit Study: Pacific Earthquake Engineering Research Center report no. 2016/06, $90 \mathrm{p}$.

Kamigaichi, O., Saito, M., Doi, K., Matsumori, T., Tsukada, S., Takeda, K., Shimoyama, T., Nakamura, K., Kiyomoto, M., and Watanabe, Y., 2009, Earthquake early warning in Japan-Warning the general public and future prospects: Seismological Research Letters, v. 80, no. 5, p. 717-726, https://doi.org/10.1785/gssrl.80.5.717.

Kanamori, H., 2005, Real-time seismology and earthquake damage mitigation: Annual Review of Earth and Planetary Sciences, v. 33, p. 195-214, https://doi.org/10.1146/annurev. earth.33.092203.122626.

Kodera, Y., Saitou, J., Hayashimoto, N., Adachi, S., Morimoto, M., Nishimae, Y., and Hoshiba, M., 2016, Earthquake early warning for the 2016 Kumamoto earthquake-Performance evaluation of the current system and the next-generation methods of the Japan Meteorological Agency: Earth, Planets and Space, v. 6, no. 202, https://doi.org/10.1186/s40623-0160567-1.

Kodera, Y., Yamada, Y., Hirano, K., Tamaribuchi, K., Adachi, S., Hayashimoto, N., Morimoto, M., Nakamura, M., and Hoshiba, M., 2018, The Propagation of Local Undamped Motion (PLUM) method-A simple and robust seismic wavefield estimate approach for earthquake early warning: Bulletin of the Seismological Society of America, v. 108, no. 2, p. 983-1003, https://doi.org/10.1785/0120170085.

Kohler, M.D., Cochran, E.S., Given, D., Guiwits, S., Neuhauser, D., Hensen, I., Hartog, R., Bodin, P., Kress, V., Thompson, S., Felizardo, C., Brody, J., Bhada, R., and Schwarz, S., 2018, Earthquake early warning ShakeAlert system-West coast wide production prototype: Seismological Research Letters, v. 89, no. 1, p. 99-107, https://doi.org/10.1785/0220170140.

Kong, Q., Allen, R.M., Schreier, L., and Kwon, Y-W., 2016a, MyShake-A smartphone seismic network for earthquake early warning and beyond: Science Advances, v. 2, 8 p., https://doi.org/10.1126/sciadv.1501055.

Kong, Q., Allen, R.M., and Schreier, L., 2016b, MyShakeInitial observations from a global smartphone seismic network: Geophysical Research Letters, v. 43, p. 9588-9594, https://doi.org/10.1002/2016GL070955.

Kuyuk, H.S. and Allen, R.M., 2013, Optimal seismic network density for earthquake early warning - A case study from California: Seismological Research Letters, v. 84, no. 6, p. 946-954, https://doi.org/10.1785/0220130043. 
Lawrence, J.F., Cochran, E.S., Chung, A., Kaiser, A., Christensen, C.M., Allen, R., Baker, J.W., Fry, B., Heaton, T., Kilb, D., Kohler, M.D., and Taufer, M., 2014, Rapid earthquake characterization using MEMS accelerometers and volunteer hosts following the M 7.2 Darfield, New Zealand, earthquake: Bulletin of the Seismological Society of America, v. 104, p. 184-192, https://doi.org/10.1785/0120120196.

Lindsey N.J., Martin, E.R., Dreger, D.S., Freifeld, B., Cole, S., James, S.R., Biondi, B., Ajo-Franklin, J.B., 2017, Fiber-optic network observations of earthquake wavefields: Geophysical Research Letters, v. 44, p. 11792-11799, https://doi. org/10.1002/2017GL075722.

Meier, M-A., 2017, How "good" are real-time ground motion predictions from Earthquake Early Warning systems?: Journal of Geophysical Research, v. 122, p. 5561-5577, https://doi.org/10.1002/2017JB014025.

Melgar, D., Bock, Y., Sanchez, D., and Crowell, B.W., 2013, On robust and reliable automated baseline corrections for strong motion seismology: Journal of Geophysical Research-Solid Earth, v. 118, p. 1177-1187, https://doi.org/10.1002/jgrb.50135.

Melgar, D., and Hayes, G.P., 2017, Systematic observations of the slip pulse properties of large earthquake ruptures: Geophysical Research Letters, v. 44, p. 9691-9698, https://doi.org/10.1002/2017GL074916.

Melgar, D., LeVeque, R.J., Dreger, D.S., and Allen, R.M., 2016, Kinematic rupture scenarios and synthetic displacement dataAn example application to the Cascadia subduction zone: Journal of Geophysical Research Solid Earth, v. 121, p. 6658-6674, https://doi.org/10.1002/2016JB013314.

Minson, S.E., Brooks, B.A., Glennie, C.L., Murray, J.R., Langbein, J.O., Owen, S.E., Heaton, T.H., Iannucci, R.A., and Hauser, D.L., 2015, Crowdsourced earthquake early warning: Science Advances, v. 1, no. 3, 7 p., https://doi.org/10.1126/sciadv.1500036.

Minson, S.E., Meier, M-A., Baltay, A.S., Hanks, T.C., and Cochran, E.S., 2018, The limits of earthquake early warning-Timeliness of ground motion estimates: Science Advances, v. 4, no. 3, https://doi.org/10.1126/sciadv. aaq0504.

Minson, S.E., Murray, J., Langbein, J., and Gomberg, J., 2014, Real-time inversions for finite fault slip models and rupture geometry based on high-rate GPS data: Journal of Geophysical Research, v. 119, no. 4, p. 3201-3231, https://doi.org/10.1002/2013JB010622.

Minson, S.E., Wu, S., Beck, J.L., and Heaton, T.H., 2017, Combining multiple earthquake models in real time for earthquake early warning: Bulletin of the Seismological Society of America, v. 107, no. 4, p. 1868-1882, https://doi.org/10.1785/0120160331.
Nakamura, Y., 1988, On the urgent earthquake detection and alarm system (UrEDAS) [abs.]: Proceedings of the 9th World Conference on Earthquake Engineering, v. VII, p. 673-678.

Nakamura, M., Hoshiba, M., Matsui, M., Hayashimoto, N., and Wakayam, A., 2013, Feedback about earthquake early warning-Questionnaire survey after the 2011 Tohoku earthquake ( $\left.\mathrm{M}_{\mathrm{w}} 9.0\right)$ [abs.]: American Geophysical Union Spring Meeting Abstract S43A-02.

Nakamura, Y., Saita, J., and Sato, T., 2011, On an earthquake early warning system (EEW) and its applications: Soil Dynamics and Earthquake Engineering, v. 31, no. 2, p. 127-136.

Ross, Z.E., Meier, M-A., Hauksson, E., 2018, P wave arrival picking and first-motion polarity determination with deep learning: Journal of Geophysical Research, v. 123, p. 5120-5129, https://doi.org/10.1029/2017JB015251.

Ruhl, C.J., Melgar, D., Grapenthin, R., and Allen, R.M., 2017, The value of real-time GNSS to earthquake early warning: Geophysical Research Letters, v. 44, p. 8311-8319, https://doi.org/10.1002/2017GL074502.

Rydelek, P., and Horiuchi, P., 2006, Earth science-Is earthquake rupture deterministic?: Nature, v. 442, no. E5E6, https://doi.org/10.1038/nature04963.

Strauss, J.A., and Allen, R.M., 2016, Benefits and costs of earthquake early warning: Seismological Research Letters, v. 87, no. 3, p. 765-772, https://doi. org/10.1785/0220150149.

Suárez, G., Novelo, D., and Mansilla, E., 2009, Performance evaluation of the Seismic Alert System (SAS) in Mexico City-A seismological and a social perspective: Seismological Research Letters, v. 80, no. 5, p. 707-716, https://doi.org/10.1785/gssrl.80.5.707.

Wirth, E.A., Frankel, A.D., and Vidale, J.E., 2017, Evaluating a kinematic method for generating broadband ground motions for great subduction zone earthquakes-

Application to the $\mathrm{M}_{\mathrm{w}} 8.3$ Tokachi-Oki earthquake: Bulletin of the Seismological Society of America, v. 107, p. $1737-$ 1753, https://doi.org/10.1785/0120170065.

Wu, S., Beck, J.L., and Heaton, T.H., 2013, ePADEarthquake probability-based automated decision-making framework for earthquake early warning: Computer-Aided Civil and Infrastructure Engineering, v. 28, no. 10, p. 737-752, https://doi.org/10.1111/mice.12048.

Wu, S., Cheng, M-H., Beck, J.L., and Heaton, T.H., 2014, Uncertainty analysis of decision making for early warning application in elevator control [abs.]: 10th U.S. National Conference on Earthquake Engineering Proceedings. 
Wu, Y-M., Kanamori, H., Allen, R., and Hauksson, E., 2007, Determination of earthquake early warning parameters, $\tau_{\mathrm{C}}$ and Pd, for southern California: Geophysical Journal International, v. 170, p. 711-717, https://doi.org/10.1111/j.1365246X.2007.03430.x.

Wu, Y-M., Shin, T-C., and Tsai, Y-B., 1998, Quick and reliable determination of magnitude for seismic early warning: Bulletin of the Seismological Society of America, v. 88, no. 5, p. 1254-1259.

Yamada, M. and Heaton, T., 2008, Real-time estimation of fault rupture extent using envelopes of acceleration: Bulletin of the Seismological Society of America, v. 98, p. 607-619, https://doi.org/10.1785/0120060218.
Yang, B.M., Huang, T-C., Wu, Y-M., 2018, ShakingAlarm-A nontraditional regional earthquake early warning system based on time-dependent anisotropic peak ground-motion attenuation relationships: Bulletin of the Seismological Society of America, v. 108, no. 3A, p. 1219-1230, https://doi.org/10.1785/0120170105.

Ye, L., Lay, T., Kanamori, H., and Rivera, L., 2016, Rupture characteristics of major and great $\left(M_{w} \geq 7.0\right)$ megathrust earthquakes from 1990 to 2015-1. Source parameter scaling relationships: Journal of Geophysical Research, v. 121, p. 821-844, https://doi.org/10.1002/2015JB012426. 
